\title{
Automated imagery orthorectification pilot
}

\author{
E. Terrence Slonecker ${ }^{\mathrm{a}, \mathrm{b}}$, Brad Johnson ${ }^{\mathrm{c}, \mathrm{d}}$, and Joe McMahon ${ }^{\mathrm{c}}$ \\ ${ }^{a}$ U.S. Geological Survey (USGS), Eastern Geographic Science Center, 12201 Sunrise Valley \\ Drive, 521 National Center \\ Reston, Virginia 20192 \\ tslonecker@usgs.gov \\ ${ }^{\mathrm{b}}$ Formerly with: U.S. Environmental Protection Agency, Office of Research and \\ Development, Las Vegas, Nevada \\ ${ }^{c}$ SRA International Incorporated \\ Fairfax, Virginia 22033 \\ Joe_McMahon@sra.com \\ ${ }^{\mathrm{d}}$ Now with: LMN Solutions \\ McLean, VA 22102 \\ brad.johnson@Imnsolutions.com
}

\begin{abstract}
Automated orthorectification of raw image products is now possible based on the comprehensive metadata collected by Global Positioning Systems and Inertial Measurement Unit technology aboard aircraft and satellite digital imaging systems, and based on emerging pattern-matching and automated image-to-image and control point selection capabilities in many advanced image processing systems. Automated orthorectification of standard aerial photography is also possible if a camera calibration report and sufficient metadata is available. Orthorectification of historical imagery, for which only limited metadata was available, was also attempted and found to require some user input, creating a semi-automated process that still has significant potential to reduce processing time and expense for the conversion of archival historical imagery into geospatially enabled, digital formats, facilitating preservation and utilization of a vast archive of historical imagery. Over 90 percent of the frames of historical aerial photos used in this experiment were successfully orthorectified to the accuracy of the USGS 100K base map series utilized for the geospatial reference of the archive. The accuracy standard for the $100 \mathrm{~K}$ series maps is approximately 167 feet (51 meters). The main problems associated with orthorectification failure were cloud cover, shadow and historical landscape change which confused automated image-to-image matching processes. Further research is recommended to optimize automated orthorectification methods and enable broad operational use, especially as related to historical imagery archives.
\end{abstract}

Keywords. orthorectification, automated orthorectification, georegistration, digital metadata, historical imagery, archival imagery, Digital Ortho Quads (DOQ), Digital Ortho Quarter Quads (DOQQ).

\section{INTRODUCTION}

Remote sensing is becoming an increasingly important science for advancing the understanding of environmental processes, conditions, changes, and for monitoring both human and ecological health. Key societal decision making processes such as emergency response and land use planning routinely rely on information derived from imagery and remote sensing systems. New sensors, systems and commercially available imagery have changed many aspects of modern life. However, even with the significant advancements in sensor technology and image availability, one of the most important and enduring aspects of 
all remotely sensed data is the simple fact that each image represents a sample point in time that is preserved for countless future applications.

Acquisition of aerial photos and other aircraft-based imagery has been regularly accomplished since the 1920 s and represents a rich source of historical observation data. The value of historical imagery for many applications has been documented by [1-8]. However, the great majority of this data still exists in analog form only (film and/or paper), often with minimal metadata and cannot be easily accessed and/or utilized except through timeconsuming manual search and indexing methods. Further, to be utilized in modern Geographic Information Systems (GIS), analog-to-digital conversion and spatial georeferencing must be accomplished, which is a slow, labor-intensive, time consuming effort. One of the great data management challenges for the geographic community will be the development of a strategy for the remedial analog to digital conversion and spatial georeferencing of the historical imagery holdings of the world.

Orthorectification is a three-dimensional photogrammetric correction of raw imagery that digitally renders the image into a cartographically corrected map-quality image tied to an earth coordinate system. The process requires knowledge of the camera system (lens distortions, focal length), the collection parameters (flying height, percentage of overlap...) and knowledge of the imaged terrain such as real-world coordinates and topographic elevation. These parameters feed complex photogrammetric equations which create mathematical relationships between the sensor, the image and the target surface. Until recently, most of these parameters were manually input into a computer model and processed by skilled technicians. However, with the advent of digital imaging systems, on-board Global Positioning Systems (GPS) and Inertial Measurement Unit (IMU) technology, pattern recognition technology, digital databases of previous orthorectified images and digital elevation models (DEM), the entire orthorectification process can now be automated [9-11], resulting in tremendous reduction in the cost and time for processing imagery.

To realize the full breadth of remote sensing information potential relevant to environmental decision-making, the enormous archives of analog remote sensing data must be converted to digital format and geo-referenced into a geodetic coordinate system. With the emergence of automated orthorectification technology, the opportunity exists to greatly increase the base of remotely sensed information and to efficiently serve that information, via GIS/internet services, directly to the decision makers.

This paper reports on a pilot research project to apply emerging automated orthorectification technology to historical imagery archives and evaluate the advantages and disadvantages that this technology presents.

\section{BACKGROUND}

In an age of integrated spatial analysis, imagery is most useful for decision makers, when it can be fully integrated with other data sets in a GIS environment. To do this, a process of geo-registration must be accomplished where the image is tied to a known ground coordinate system and re-sampled into map-quality spatial properties. Orthorectification is the same process but includes elevation data to further refine the location of each image pixel. The essential problem is that this orthorectification process is slow, time consuming and requires trained remote sensing technicians to perform. The result is that new imagery often does not get into a usable analytical form for many weeks after acquisition, even in emergency situations. This also means that much of our historical holdings of analog aerial photography will never be converted into this digital, geospatial format, simply because the process is too expensive.

Although small compared to the imagery archives of other agencies like the United States Department of Agriculture (USDA) and the U.S. Geological Survey (USGS), the Environmental Protection Agency (EPA) currently maintains a Remote Sensing Archive 
(RSA) of imagery holdings that includes over 5,000 rolls and 75,000 individual frames of aerial photos and associated products that exist primarily in analog form only. For these imagery holdings to be fully effective and functional, it requires the massive conversion of the RSA's analog film holdings to digital, geo-referenced form, along with the development of appropriate metadata. Although this conversion process is currently underway, it is a time and labor-intensive process that will require at least ten years to complete at current production rates. An automated ortho-rectification process promises to be a potentially major breakthrough in the overall utilization of imagery for geospatial analysis. Imagery that once took weeks to process can now be processed in minutes for emergency and time-critical responses. Additionally, we will have a practical and cost-efficient method for converting historical imagery holdings into an effective geospatial format.

The Automated Imagery Orthorectification Pilot (AIORP) system is comprised of the best-of-breed Commercial Off The Shelf (COTS) products that are compliant with Open Geospatial Consortium interface specifications and are integrated through platformindependent code that enables the data workflow and processing. The AIORP is designed to provide a system capable of fully automated orthorectification of full-frame commercial satellite images. It is a complete end-to-end system where no user interaction is required, except for the submittal of the raw images. The control data required for automated orthorectification, controlled image base (CIB) or digital ortho quad (DOQ) and digital terrain elevation data (DTED, DEM), are discovered dynamically and are automatically used by the system without user intervention. The architecture is scalable and allows for multiple orthorectification processes to be running concurrently in a distributed fashion across multiple hardware elements made available to the system. The AIORP system is based on COTS technology, in this case a combination of the Ionic (Liege, Belgium) geospatial catalog and PCI (Ontario, Canada) Geomatics orthorectification. Processing is done on a dedicated hardware cluster that is capable of approximately 20 images per hour.

Until very recently, georeferencing and orthorectification were manual processes that were accomplished by skilled photogrammetric technicians, first by analog instruments that reprojected the corrected image into cartographically corrected format, and then later by

digital photogrammetric processing. Under the best circumstances, the entire orthorectification process was, and still is, technically difficult, time-consuming and laborintensive. This is the primary reason that most of the historical imagery that today exists in the many film archives of the government and private industry, has NOT been converted into a geospatial, GIS friendly format. It is simply too expensive.

\subsection{The Evolution of Automated Orthorectification}

Although not fully implemented, automated orthorectification is becoming an accepted image processing capability in the world of remote sensing. Several commercial image processing vendors offer standard processing packages $[12,13]$ for an automated imagery orthorectification process and related applications for radar and other types of imagery. Several research applications have shown that automated orthorectification of satellite imagery can be employed as a standard component of preliminary image processing [14-17]. A survey of image registration techniques can be found in Brown (1992) and Zitova and Flusser $(2003)[18,19]$ and there are many applications of automated image registration or orthorectification as related to landscape change detection [20]. Some notable examples of automated registration or orthorectification techniques include the following.

Liu and Chen (2009) [21] developed a methods for automated orthorectification of Formosat-2 imagery using a four-step process that includes; 1) automatic extraction of Ground Control Regions, (GCRs) (2) fast image-to-image matching, 3) iterating and filtering of GCRs, and 4) rigorous orthorectification. Results showed that the accurate orthoimage 
with a root mean square error of less than 1.5 pixels could be automatically generated from one standard Formosat-2 in 55 minutes. This new method has been incorporated into the Formosat-2 automatic image processing system and is currently being used to produce orthoimages on a daily-basis

Leprince et al. (2007) [22]. achieved an automated and precise orthorectification of SPOT imagery by developing an optimized model of the platform geometry that is able to achieve $1 / 50$ pixel accuracy for SPOT images and was successfully used to monitor subtle ground deformations due to seismic activity.

The National Aeronautics and Space Administration (NASA) recently developed an automated orthorectification software system for use with Synthetic Aperture Radar (SAR) data that allows users of SAR data to form processed images and other high-level products that are free of distortion due to the imaging geometry or topography changes [23].

\subsection{Automated Image Matching and Control Point Generation}

The current level of automation in image rectification is made possible by both area and feature-based automated image matching techniques that were developed by several researchers in the 1990s $[24,25]$. In the area based techniques, a small window of pixels in a target image is compared to the same window of pixels in a reference image. Correspondence or correlation measures are used to judge the goodness-of-fit and the target or reference window may be adjusted to determine if there is a better fit which is generally determined by a cross-correlation procedure [24]. Fast Fourier Transforms are used for each window with the window centers used as control point for the transformation parameters [24, 26].

Feature-based methods utilize control points based on contrast thresholding in the images, edge, boundaries and other identifiable point features usually derived from some type of image segmentation procedure. Features could also come from a control-point database that may have been developed over time and repeated rectification processing.

Feature and control point correspondence is then processed and the image resampled based on a variety of potential mathematical techniques including linear and polynomial regression, structural programming and other techniques [24]. Area-based techniques work best when there is a high degree of similarly in the target and reference images but they tend to fall apart when complex warping transformations are involved. Feature-based techniques are more robust and work better when the there are major misalignment issues and therefore complex transformations which are computationally more rigorous [24].

\section{THE AIORP EXPERIMENT}

This project was funded by the 2006 Environmental Protection Agency's (EPA) Advanced Monitoring Initiative (AMI) [27] Project 31, Automated Imagery Orthorectification Pilot (AIORP), and was collaboration between the EPA and U.S. Intelligence Community (IC) conducted jointly by EPA/IC with the contract assistance of SRA Incorporated. The goal of the AIORP was to develop and test an automated imagery geo-rectification capability that would enable raw historical imagery products to be quickly, accurately and efficiently transformed into cartographically-corrected and geo-spatially referenced remote sensing information products that can be served in near-real time to a community of internal and external scientific users. This system utilizes several emerging geospatial and photogrammetric software capabilities that enable automated positioning, retrieval of ortho and elevation information, internal and external control point establishment, and a full orthorectification and mosaic capability. 
This AIORP system is patterned after an IC prototype that involved strictly commercial, off-the-shelf components and software [10]. By significantly increasing the digital base of remotely sensed information and by making it easily accessible via GIS/internet services, this research could provide important new monitoring capabilities to major research communities such as the U.S. Geological Survey's (USGS) Land remote Sensing (LRS) [28] program, the Global Climate Change [29| and Global Earth Observation (GEO) [30] communities via a practical methodology to convert and preserve vulnerable and irreplaceable historical remote sensing information and facilitate its use in environmental decision-making.

\subsection{The Automated Imagery Orthorectification Process.}

The potential for automated imagery georegistration and orthorectification has been demonstrated by a number of researchers [31-33]. In general, two emerging technological capabilities make automated orthorectification possible. First is the digital metadata that is recorded and delivered with the imagery based on the satellite sensor or digital camera platform, instrument and collection parameters. The GPS/IMU data that is collected often contains all of the critical photogrammetric data necessary, such as geographic location, flying height, camera lens parameters, tip, tilt, yaw and $\mathrm{x}, \mathrm{y}$ and $\mathrm{z}$ coordinates and estimated errors. Second is automated image-to-image matching and control point generation. With this data the imagery is basically delivered with a specific math model for the sensors or rational polynomial coefficients (RPC) which fully enable the orthorectification process. All that is then needed is an existing orthoimage from a standard database, such as the Controlled Image Base (CIB)) or Digital Orthophoto Quad (DOQ) databases, an elevation model, such as the USGS National Elevation Dataset (NED) and a scripting language to provide I/O and control the process flow. [34-36]

From a conceptual standpoint, the AIORP process basically works in the following way:

1. An image is automatically ingested into the processing node.

2. Interior orientation parameters (a sensor specific math model, or focal length, principal point of symmetry, radial lens distortion, flight height, fiducial marks, etc) are read from a file or from digital metadata or header file that accompanies the image.

3. The basic geographic footprint is calculated for the image.

4. A digital elevation model and reference ortho-image are extracted from existing databases covering the geographic footprint of the image.

For this project, the digital elevation models were extracted from the U.S. Geological Survey's NED database. The NED is the primary elevation data product of the USGS and is a seamless dataset with the best available raster elevation data of the conterminous United States, Alaska, Hawaii, and territorial islands. The NED has a resolution of one arc-second (approximately 30 meters) for the conterminous United States and an absolute spatial accuracy of 7 meters,

The geographic footprint of the target image is then used to retrieve a geometrically corrected image from a seamless database of existing orthorectified imagery. For this experiment two sets of existing orthoimagery were utilized; the National Geospatial 
Intelligence Agency (NIMA) Controlled Image base (CIB) and the U. S. Geological Survey's Digital Orthophoto Quad (DOQ) program $[35,36]$

The Controlled Image Base (CIB) is a dataset of orthophotos, made from rectified grayscale aerial images. CIB supports various military and intelligence geospatial information requirements. CIB data are produced from digital source images that can be converted to meet the requirements of the CIB specification at one of the registered resolutions defined in MIL-STD-2411-1. The accuracy of CIB products can vary but for this application it was 5 meters [35].

A USGS digital orthophoto quadrangle (DOQ) is a computer-generated image of an aerial photograph in which image displacement caused by terrain relief and camera tilts has been removed. It combines the image characteristics of a photograph with the geometric qualities of a map. Imagery resolution is one meters and the geodetic spatial accuracy is 7 meters root-mean square-error [36].

5. Image-to-image matching is accomplished based on the pattern recognition, and control points are generated. or read from a file.

6. Exterior orientation parameters are calculated.

7. Rigorous orthorectification is performed.

8. After a basic quality control screening, the new ortho image is delivered to a master database or published to a web service.

\subsection{Hardware Configuration}

The actual hardware and software configuration of the AIORP process was altered from the original prototype because the project focused primarily on the question of orthorectification and not on overall end-user based distribution and utilization. However, the configuration is reported here for sake of clarity. The prototype system, as reported by Smith et al. [10] and shown in Figure 1, consists of a 4 terabyte (TB) RAID array for storage, a front-end server for storage and web distribution, an applications server for geospatial and photogrammetric control and a database server, all on a 1 gigabit $(\mathrm{gb})$ ethernet with eight blade processing workstations for photogrammetric processing and orthorectification production. The actual configuration in this experiment included a front end server, a 4 TB RAID and three blade processing workstations. 


\subsection{Software Configuration}

The software capabilities to perform this type of workflow processing are now becoming more widely available in the remote sensing community. For this study PCI Geomatica (Richmond Hill, Ontario, Canada) was utilized with shell scripts used to control the workflow process. Open source versions of orthorectification are available in packages such as Orthomap :

(http://www.remotesensingtools.com/2007/12/10/auto-orthorectification-tool-orthomap/)

and, OSSIM

(http://ossim.telascience.org/ossimdata/Documentation/OSSIM_GUI_howto.doc).

\section{THE CRITCAL ROLE OF DIGITAL METADATA}

With the advent of modern geospatial technologies, such as Global Positioning Systems (GPS) and Inertial Measurement Unit (IMU) capabilities, remote sensing satellites and aircraft can capture critical photogrammetric parameters, such as nadir position, flight height,

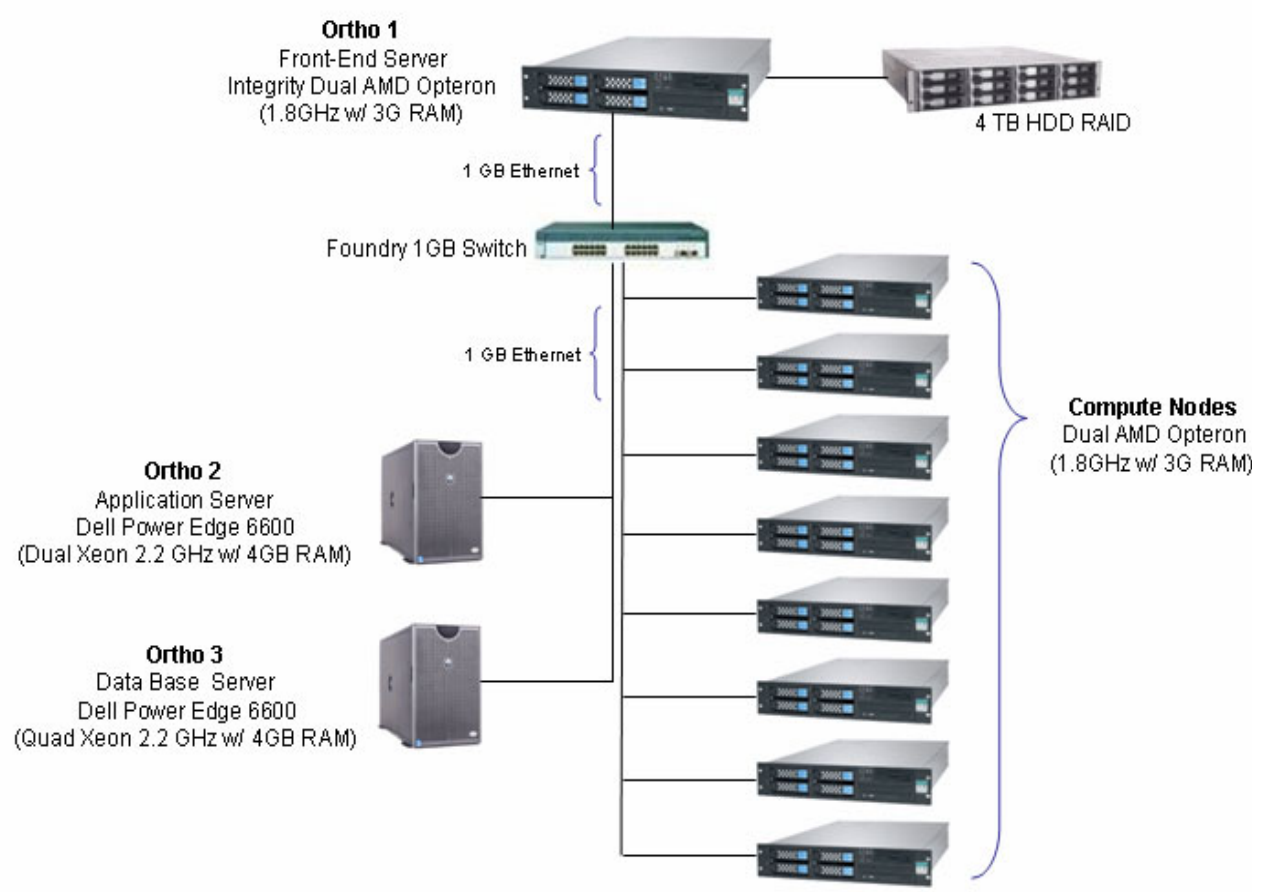

Fig. 1. The original auto orthorectification processing cluster [10]. 
tip, tilt, pitch, yaw...etc, with considerable precision and as an integral part of the image data header file or the associated metadata file. This greatly facilitates the basic mathematical resection that is the fundamental math process in orthorectification. However, when dealing with historical imagery, this type of metadata is not likely to be available and two special cases must be considered for ortho-image processing. First, a digital metadata file can be created from critical camera, sensor and platform parameters and existing analog data such as camera calibration reports and flights logs, and second, this information cannot be developed from existing analog metadata and a generic metadata file must be created from a limited information such as fiducial locations, scale and flight height, all which can be measured from the image. In either case the overall process must require some user input and becomes semiautomated.

Although not as attractive as a fully automated system, the semi-automated process still represents tremendous efficiencies over manual methods. Since most historical aerial photography is collected and stored on rolls of film, usually taken with the same camera over the same basic area, even a semi-automated orthorectification capability would permit an analyst to set up one metadata file for the entire roll and run the automated orthorectification process on several hundred frames of imagery with minimal user input. Manual orthorectification methods often take upwards of 1 hour per frame so that the efficiencies to be realized are still very significant.

\section{THE PROCESSING TRIALS}

Several iterative trials and several individual automated ortho-image processing tests were conducted during 2006. Also, the previous prototype results are reported here for reference. The results of both trials are summarized in Table 1. All imagery was 11-bit panchromatic or black and white. The satellite images averaged about 13,000 x 13,000 pixels at one-meter ground resolution. The aerial photos averaged about $14,000 \times 14,000$ pixels at variable ground resolution but usually sub-meter. The initial test involved satellite imagery with digital metadata and was very efficient except where the metadata was insufficient (i.e., corrupted or incomplete). This was a test of a fully automated system and no attempts were made to develop a solution manually or in a semi-automated manner. Results show that full satellite scenes could be completely orthorectified to CIB standards in an average of less than 15 minutes per scene. The EPA tests in Waynesboro, Virginia and Leviathan Mine, California were small tests designed around specific potential problems [37]. In Waynesboro, historical imagery dating back to 1937 was utilized to determine if basic landscape change would affect the automated control point and image-to-image registration processes. In fact, some of the 1937 imagery failed the orthorectification process because of significant level of landscape change that made automated image matching and control point matching very difficult. Figure 2 shows the 1937 and 1994 images of a portion of the area, demonstrating the level of landscape change involved [37].

In the Leviathan test, extreme elevation change proved to extend the processing time significantly, as might be expected, but low contrast and poor quality in the reference DOQ data appeared to be the biggest problem. In the EPA-Ohio test, relatively smooth and efficient semi-automated orthorectification was achieved with high quality imagery over a relatively flat terrain. The average processing time, once the manual set-up was accomplished, was only 2.25 minutes per frame [37]..

However, the major test was conducted during August and September of 2006 at the EPA Remote Sensing Archive in Las Vegas, Nevada. Random rolls of archival historical photos were selected and scanned at approximately 1800 dpi (approximately a 15 micron scan). DOQ and NED data were collected for reference and processing purposes. Semi-automated set-up methods were used which involved the editing of basic camera and photogrammetric 
parameters and the manual selection of a minimum (3-7) number of control points per photo from the reference ortho [37].

The results of all the automated orthorectification experiments are listed in Table 1. In general, the semi-automated process provided acceptable results with 395 out of 436 images being orthorectified to some level of accuracy. Although many did not meet the accuracy standard of the USGS DOQ program, they still are acceptable for basic database storage and for geospatial imagery archive purposes. Also, additional research and development will likely lead to improvements in the spatial accuracy of the orthorectification process.

However, the major test was conducted during August and September of 2006 at the EPA Remote Sensing Archive in Las Vegas, Nevada. Random rolls of archival historical photos were selected and scanned at approximately 1800 dpi. DOQ and National Elevation Data were collected for reference and processing purposes. Semi-automated set-up methods were used which involved the editing of basic camera and photogrammetric parameters and the manual selection of a minimum number of control points.

Table 1. Summary of Auto-Orthorectification Results.

\begin{tabular}{|c|c|c|c|c|c|c|c|c|c|}
\hline $\begin{array}{l}\text { Test } \\
\text { Name }\end{array}$ & $\begin{array}{l}\text { Platform } \\
\text { Type/ } \\
\text { Sensor }\end{array}$ & $\begin{array}{l}\text { Image } \\
\text { Type }\end{array}$ & $\begin{array}{l}\text { Avg } \\
\text { Image } \\
\text { Size }\end{array}$ & Digit & $\begin{array}{l}\text { Total } \\
\text { Images }\end{array}$ & $\begin{array}{l}\text { Completed/ } \\
\text { Failed } \\
\text { Orthos }\end{array}$ & $\begin{array}{l}\text { Average } \\
\text { Time/Image } \\
\text { (mm:ss) }\end{array}$ & $\begin{array}{l}\text { RMSE } \\
\text { (meters) }\end{array}$ & $\begin{array}{c}\text { Reason for } \\
\text { Failures }\end{array}$ \\
\hline IC-1 & $\begin{array}{l}\text { Satellite/ } \\
\text { (Ikonos) }\end{array}$ & Pan & $328 \mathrm{mb}$ & $11 \mathrm{bit}$ & 31 & $22 / 9$ & $14: 55$ & $<5 \mathrm{~m}$ & $\begin{array}{r}\text { corrupted } \\
\text { metadata }\end{array}$ \\
\hline $\begin{array}{l}\text { EPA } \\
\text { Virginia }\end{array}$ & $\begin{array}{l}\text { Aircraft/ } \\
\text { camera }\end{array}$ & B\&W & $206 \mathrm{mb}$ & 11 bit & 10 & $8 / 2$ & $3: 25$ & $<10 \mathrm{~m}$ & $\begin{array}{l}\text { landscape } \\
\text { change }\end{array}$ \\
\hline $\begin{array}{l}\text { EPA } \\
\text { Ohio }\end{array}$ & $\begin{array}{l}\text { Aircraft/ } \\
\text { camera }\end{array}$ & B\&W & $212 \mathrm{mb}$ & 11 bit & 61 & $61 / 0$ & $2: 25$ & $<10 \mathrm{~m}$ & N/A \\
\hline $\begin{array}{l}\text { EPA } \\
\text { Leviathan }\end{array}$ & $\begin{array}{l}\text { Aircraft/ } \\
\text { camera }\end{array}$ & B\&W & $208 \mathrm{mb}$ & 11 bit & 5 & $5 / 0$ & 48:00 & $<15 \mathrm{~m}$ & N/A \\
\hline $\begin{array}{l}\text { EPA } \\
\text { Nevada }\end{array}$ & $\begin{array}{c}\text { Aircraft/ } \\
\text { camera }\end{array}$ & $\mathrm{B} \& W$ & $224 \mathrm{mb}$ & 11 bit & 436 & $395 / 41$ & $31: 35$ & $<45 \mathrm{~m}$ & $\begin{array}{l}\text { Low contrast } \\
\text { Open water } \\
\text { Geometery } \\
\text { Cloud Cover } \\
\text { Insufficient } \\
\text { Metadata }\end{array}$ \\
\hline
\end{tabular}



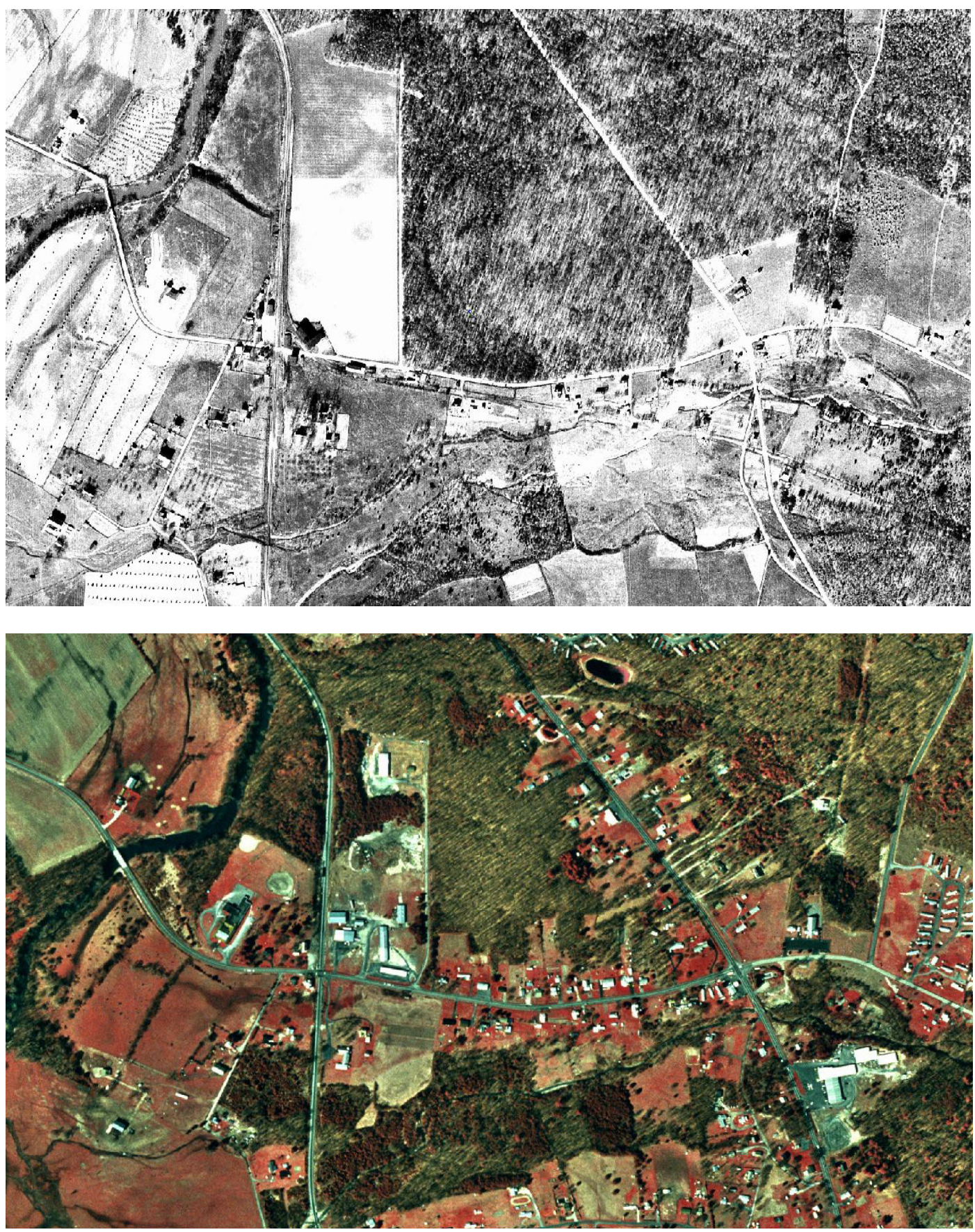

Fig. 2. A 1937 image (top) and a 1994 image (bottom) of the area around Waynesboro, Virginia demonstrating the level of landscape change that can cause problems with automated image-toimage matching and control point identification that are a fundamental process in automated or semi-automated image orthorectification. 
Of the images that failed during the orthorectification process, the primary reasons for failure include:

\author{
Incorrect or insufficient metadata, \\ Panoramic or oblique camera orientations, \\ Too much landscape change between the historical image and the reference \\ image, \\ Open water, shadows or cloud cover in the raw image, \\ Poor tonal quality or low contrast in the reference DOQQ image.
}

\title{
7 DISCUSSION
}

Although a limited trial, this project represents an important initial step in the development of an automated and/or semi-automated orthorectification process that can be functional even for historical imagery for which little or no metadata exists. An initial metadata file can be created from the analog information such as flight logs and camera calibration reports. Even if this analog data can not be recovered, a semi-automated orthorectification process can still be accomplished by estimating the collection parameters and manually selecting a small number of control points between the database ortho image and the raw image. In terms of processing efficiency, this is still a significant improvement of purely manual methods and could open the door to the orthorectification of a huge global database of historical aircraft and satellite imagery. In this experiment, single frames were processed independently so that issues related to individual image characteristics and/or geometries could be easily identified. However, in typical photogrammetric mapping operations an aero-triangulation solution and bundle adjustment could be easily be performed and would be likely to improve results.

The primary problems are a lack of accurate metadata, including camera calibration reports and landscape change over time which complicates image registration and automated control point generation. These could be potentially overcome by gaining access to the archive of camera reports, especially in a digital format. Further, landscape change could be minimized by creating historical databases of orthorectified imagery to be used as the base map.

\section{CONCLUSIONS AND RECOMMENDATIONS}

\subsection{Findings}

Significant findings of this research include both the relative ease with which automated orthorectification can be accomplished when sufficient metadata and control information exist, and, the fact that historical imagery, for which little or no metadata exists, can still be orthorectified with a semi-automated process, which is still significantly more efficient than traditional methods. Further research and development in automated and semi-automated orthorectification is clearly justified and strongly encouraged. Logical development of automated or semi-automated orthorectification processing might include the following tasks. 


\subsection{Camera Calibration Database}

The creation of a comprehensive camera calibration database would be extremely beneficial to model setup / metadata problems. The USGS Optical Science Laboratory has been providing camera calibration services for decades and maintains a rich data base of camera calibration reports [38]. Although most of these currently exist in analog form, it would be clearly beneficial to the entire mapping community to have these all available in a standard $\mathrm{xml}$ format so that they could be ingested by any image processing system. The creation of a database that could feed an automated orthorectification process would represent a major improvement in process efficiency and accuracy. The USGS Optical Science Laboratory should be encouraged to create such a digital product

\subsection{Further Development of the Orthorectification Process}

It is clear that some of the problems with the historical imagery rectification could be improved by automating and including several standards mapping methods such as performing an aero triangulation solution and bundle adjustment. Also, the development of a generic air photo camera model could improve the overall process flow.

\subsection{Historical Ortho and DEM Databases}

The problem with landscape change confusing automated registration could be solved by creating temporal orthoimage databases, especially in urban areas where landscape change is likely to be more pronounced. Further, this concept could also be extended to historical DEM databases, especially in areas of major topographic change.

\subsection{Second Generation Orthophoto Processing}

There are some natural parallels here with an emerging concept of second-generation orthophoto processing. Second Generation Orthophoto processing is a term that refers to the production of an ortho photo that is produced from new photography and 2nd generation ground control points derived from existing maps or ortho photos and existing elevation model data [39]. There are significant resource efficiencies to be realized from this approach since it is less expensive and faster to produce. However, the accuracy budget must allow for new orthoimages with degraded accuracy. In general, this concept applies to large scale mapping projects with engineering-level map accuracy standards. The conversion of historical imagery archives is less concerned with map accuracy standard than it is with the basic conversion of historical imagery to a digital format with basic and fundamental geographic correction and reference. However, experiences with the second generation orthophoto process might provide useful insight into automated orthophoto production and should be explored in any future research effort.

\subsection{The Concept of Volumetric Appearance Modeling}

An emerging alternative technology to standard photogrammetry is that of Volumetric Appearance Modeling (VAM). The VAM concept is based on the 3-D data model of a voxel instead of the standard 2-D pixel. The voxel is a cubical volume element with both a Gaussian occupancy probability and a Bayesian distribution probability [40-41]. The voxel concept is primarily concerned with change detection, especially in the third dimension and is based on image texture and variability from multiple images from multiple look angles, as 
might be expected from wide area video surveillance [40]. However, it also represents an alternative approach to standard photogrammetric orthorectification. An automated sensor model geographic correction, based on tying voxel parameters to 3-d control points has shown promise in satellite images, achieving sub-pixel levels of registration accuracy [41]. Since the voxel already represents a 3-dimensional data structure, some of the problems with photogrammetric elevation correction are inherently minimized. Although the concept is based on existing VAM data from multiple images and additional research will be required, it could potentially offer an interesting alternative to standard orthorectification problems.

This paper has discussed a limited but successful attempt at automated and semiautomated orthorectification which could have significant implications in future utilization of historical images of all types. The ability to store, distribute, and serve historical imagery in geospatial formats from multiple sources could have significant implications for a variety of geographic research areas such as land use and land cover monitoring, global change and landscape ecology.

\section{Acknowledgments}

This project was partially funded by the U.S. Environmental Protection Agency, under EPA Grant AMI 31, by the U.S. Intelligence Community, and by the U.S. Geological Survey.

Mention of trade names or products does NOT constitute endorsement by any agency of the U.S. Government.

\section{References}

[1] T. L. Erb, W. R. Philipson, W. L.Teng, and T. Liang, "Analysis of landfills with historic airphotos," Photogram. Eng. Rem. Sens. 47, 1363-1369 (1981).

[2] S. Titus, "Survey and analysis of present or potential environmental impact sites in Woburn, Massachusetts," Proc. Ann. Meeting Am. Soc. Photogram., 538-549, Denver, CO (1982).

[3] J. G. Lyon, "The use of aerial photographs and remote sensing data in the management of hazardous waste sites," Hazardous Waste Management for the 80's, pp. 163-171, T. Sweeny, H. Bhatt, R. Sykes, and O. Sproul, Eds., Ann Arbor Science Publications, Ann Arbor, MI (1982).

[4] J. G. Lyon, "The use of maps, aerial photographs and other remote sensing data for practical evaluation of hazardous waste sites," Photogram. Eng. Rem. Sens. 53, 515519 (1987).

[5] C. Stohr, W.J. Su, P.B. DuMontelle and R.A. Griffin, "Remote sensing investigations at a hazardous waste landfill," Photogram. Eng. Rem. Sens. 53, 15551563 (1987).

[6] E. M. Barnaba, W. R. Phillipson, A. W. Ingram, and J. Pim. "The use of aerial photographs in county inventories of waste disposal sites," Photogram. Eng. Rem. Sens. 57, 1289-1296 (1991).

[7] J. D. Herman, J. E. Waites. R. M. Ponitz, and P. Etzier, "A temporal and spatial remote sensing resolution study of a Michigan superfund site," Photogram. Eng. Rem. Sens. 60, 1007-1017 (1994).

[8] E. T. Slonecker, M. J. Lacerte, and D. Garofalo. "The value of historic imagery," Earth Observ. Mag. 8, 39-41 (1999).

[9] M. Stojic, "An approach for automated orthorectification of video imagery," Proc. Am. Soc. Photogram. Rem. Sens. Ann. Conf., May 22-26, 2000, Washington D.C. (2000) 
[10] S. Smith, B. Bursey, and C. Tucker, "Auto orthorectification experiment: Phase 2 experiment report," SRA Inc, Chantilly, VA(2005).

[11] PCI Geomatics, "Orthorectification and geometric correction: Fact Sheet," PCI Geomatics Richmond Hill, Ontario, 2006) http://www.pcigeomatics.com/products/pdfs/orthorectification.pdf .

[12] ITTVIS, "ENVI orthorectification module," http://www.ittvis.com/ProductServices/ENVI/Orthorectification.aspx (2009)

[13] PCI Geomatics, "Improving airphoto processing with automated functions," http://www.pcigeomatics.com/solutions/pdf/PCI_Automated_Airphoto_Whitepaper_ v3.pdf. (2006).

[14] T. Kim and Y-J Im, "Automatic satellite image registration by combination of matching and random sample consensus," IEEE Trans. Geosci. Rem. Sens. 41, 11111117 (2003) [doi: 10.1109/TGRS.2003.811994].

[15] T. Weston. "Precise rectification of spot imagery," Photogram. Eng. Rem. Sens. 56, 247-253, (1990).

[16] P. Cheng, "Automated high-accuracy orthorectification and mosaicking of PALSAR data without ground control," Geoinform. 6, 36-38 (2007), http://www.pcigeomatics.com/pdfs/P36-38\%20GEO76LR.pdf (23 February 2009)

[17] J. A. Gonçalves and A. R. S. Marçal, "Automatic ortho-rectification of ASTER images by matching digital elevation models," Image Anal. Recog. 4633, 1265-75 (2007) [doi: 10.1007/978-3-540-74260-9_112].

[18] L. G. Brown. "A survey of image registration techniques," ACM Computing Surveys 24, 325-376 (1992) [doi: 10.1145/146370.146374].

[19] B. Zitova and J. Flusser. "Image registration methods: a survey," Image Vision Computing 21, 977-1000 (2003) [doi: 1016/S0262-8856(03)00137-9].

[20] R. J. Radke, S. Andra, O. Al-Kofahi, and B. Roysam, "Image change detection algorithms: A systematic survey," IEEE Trans. Image Process. 14, 294-307 (2005) [doi:10.1109/TIP.2004.838698].

[21] C. Liu and P. Chen, "Automatic extraction of ground control regions and orthorectification of remote sensing imagery" Opt. Exp. 17, 7970-7984 (2009) [doi:10.1364/OE.17.007970].

[22] S. Leprince, S. Barbot, F. Youb, and J.-P. Avouac, "Automatic and precise orthorectification, coregistration, and subpixel correlation of satellite images, Application to ground deformation measurements," IEEE Trans. Geosci. Rem. Sens. 45, 1529-1558 (2007) [doi:10.1109/TGRS.2006.888937].

[23] NASA, "Automated ortho-rectification software system enhances signal and image processing," Technology Development and Transfer Office, John C. Stennis Space Center, http://technology.ssc.nasa.gov/PDFs/SSC-00108_SS_NTTS.pdf

[24] X. Dai and S. Khorram, "A feature-based image registration algorithm using improved chain-code representation combined with invariant moments" IEEE Trans. Geosci. Rem. Sens. 37, 2351-2362(1999) [doi:10.1109/36.789634].

[25] L. K. G. Fonseca and B. S. Manjunah, "Registration techniques for multisensor remotely sensed imagery," Photogram. Eng. Rem. Sens. 66, 1049-1056 (1996).

[26] B. S. Reddy and B. N. Chatterji, "An FFT-based technique for translation, rotation, and scale-invariant image registration," IEEE Trans. Image Process. 5, 1266-1271 (1996) [doi: 10.1109/83.506761].

[27] U. S. Environmental Protection Agency, "Fact sheet: EPA's advanced monitoring initiative supports GEOSS," (28 September 2006) http://www.epa.gov/geoss/factsheet/ami06.pdf.

[28] U. S. Geological Survey, Land Remote Sensing Program, (13 February 2009), http://remotesensing.usgs.gov/index.php 
[29] U. S. Global Change Research Program, U. S. Global Change Research Program, (16 January 2009), http://www.usgcrp./gov

[30] U. S. Group on Earth Observations (USGEO), (23 January 2003), www.usgeo.gov.

[31] S. Baillarin, J. P. Gleyzes, C. Latry, A. Bouillon, E. Breton, L. Cunin, C. Vesco, and J. M. Delvit, "Validation of an automatic image ortho-rectification processing," IEEE Geosci. Rem. Sens. Symp. 2, 1398-1401 (2004) [doi:10.1109/IGARSS.2004.1368680].

[32] C. Chen, M-H Chen, and H-T. Li, "Fully automatic and robust approach for remote sensing image registration" Progress in Pattern Recognition, Image Analysis and Applications, vol. 4756, pp. 891-900, Springer, Berlin (2008) [doi: 10.1007/978-3540-76725-1_92].

[33] J. A. Gonçalves and A. R. S. Marçal "Automatic ortho-rectification of ASTER images by matching digital elevation models," Image Anal. Recog. 4633, 1265-75 (2007) [doi: 10.1007/978-3-540-74260-9_112]

[34] U. S. Geological Survey, "National elevation dataset," August 2006 http://ned.usgs.gov/Ned/about.asp.

[35] U. S. Department of Defense, Performance Specification, Controlled Image base (CIB), Military Specification, MIL-PRF-89041A (2001), http://www.nga.mil/ast/fm/acq/MIL-PRF-89041A\%20CIB.pdf

[36] U. S. Geological Survey, "Digital orthophoto quadrangles," Fact Sheet 057-01 (May 2001). http://egsc.usgs.gov/isb/pubs/factsheets/fs05701.html\#accuracy

[37] B. Johnson, "The EPA orthorectifcation study," SRA Inc, 30 p., Chantilly, VA (2008).

[38] S. Stephens, USGS Optical Science Laboratory, Reston, VA, Private Communication (2008).

[39] Q. A. Abdullah, "Mapping matters," Photogram. Eng. Rem. Sens. 73, 735 (2007).

[40] T. Pollard and J. L. Mundy, "Change detection in a 3-D World," IEEE Conf. Comput. Vision Pattern Recog., 1-6 (2007) [doi: 10.1109/CVPR.2007.383073]

[41] T. Pollard, I. Eden, J. Mundy, and D. Cooper, "A volumetric approach to change detection in satellite images," Photogram. Eng. Rem. Sens., under review.

E. Terrence Slonecker is a research geographer in the United States Geological Survey's Eastern Geographic Science Center. He has over 30 years of experience in remote sensing including positions with the U.S. Air Force, private industry and the Environmental Protection Agency. His current research interests include hyperspectral analysis of heavy metals and related vegetation stress. He holds a Bachelor of Science degree in Government from Christopher Newport University, a Masters of Science in Geographic and Cartographic Sciences from George mason University, and a PhD in Environmental Science and Public Policy from George Mason University. He has served as an expert witness for the Federal Government on remote sensing related matters on several occasions

Bradley Johnson has 16 years experience in the support, design and programming of information systems. He received a Bachelors of Science in Computer Information Systems from Colorado Christian University. He has aided in the design and programming of telecom billing systems, web applications, GIS systems, wide area surveillance and automatic orthorectification processing. He is currently employed by LMN Solutions as a Geo-spatial Integration Expert and Software Engineer.

Joseph McMahon is a certified program manager professional and technical director with over 18 years of experience on large scale distributed systems. He holds a B.S. in 
Computer Science from Georgia Tech and a M.S. in Computer Science and Telecommunications from the George Washington University. His career has focused largely on designing and building large scale, distributed systems, primarily for data collection and knowledge management in the geospatial, network management and security fields. Mr. McMahon joined SRA International, Inc. in 2004 after working at IBM, Lockheed Martin and other companies. He started at SRA as a technical lead on an enterprise geospatial effort focused on quickly delivering services that can be chained together in a workflow and now serves as Program Manager for a geospatial contract as well as the Enterprise Services and Solutions Division Manager for SRA's Civil Intelligence business program 